\title{
Factors Influencing Nursing Education and Teaching Methods in Nursing Institutions: A Case Study of South West Nigeria
}

\author{
Adepeju M. Lateef $^{1} \&$ Euphemia. M. Mhlongo ${ }^{1}$ \\ ${ }^{1}$ School of Nursing and Public Health, University of KwaZulu-Natal, Howard College, Durban, South Africa \\ Correspondence: Adepeju. M. Lateef, University of KwaZulu-Natal, School of Nursing and Public Health, \\ Howard College, Desmond Clarence Building 5th Floor, Durban 4001, South Africa. Tel: 27-632-134-579. E-mail: \\ princessadepejuu@gmail.com
}

Received: June 11, 2019 Accepted: August 29, 2019 Online Published: November 3, 2019

doi:10.5539/gjhs.v11n13p13

URL: https://doi.org/10.5539/gjhs.v11n13p13

\begin{abstract}
Background: Teaching and learning are like two composites sides of a coin. While the indispensability of teaching to knowledge and skill acquisition among professionals including nurses is never in doubt, certain teaching methods have been proven to yield more fruitful results than others. This study therefore explored the lived experience of nurse educators regarding teaching methods and the challenges encountered in nursing education institutions in South West Nigeria.
\end{abstract}

Methodology: A qualitative inquiry research approach was used. Fifteen nursing educators were purposively selected from three nursing institutions in South West Nigeria with at least one year of teaching experience. Data was collected through semi-structured, in-depth individual interviews with the selected participants. All interview sessions were audio recorded with participants' permission and later transcribed verbatim. Thereafter, the collected data was analyzed using thematic content analysis.

Results: The study identified a number of factors that hindering teaching methods that support students learning by nurse educators. Results showed six themes viz: Inadequate preparedness of the students for higher education; Insufficient facilitation skills of the teachers; Misconceptions about teaching practices; Resource constraints; Resistance to change; and Lack of incentives. Further analysis revealed that the dynamic changes occurring in the health care professions, require a radical shift in the way nursing students are taught, to develop them into competent nurses of the future, who are capable of using their skills to solve the health care needs of the populace.

Conclusions: The effective use of teaching methods is the cornerstone of the future of general nursing and nursing practice. Nurses need to be trained with an objective to become skilled and competent through effective teaching and learning by taking into account the diversity of higher education institutions and responding effectively to the needs of nursing educators and nursing students, as well as institutional demands.

Keywords: nurse educator, teaching methods, challenges and nursing education

\section{Introduction and Background}

It is not possible to overemphasize the significance of teaching and learning in achieving academic goals and objectives in any environment. In academic institutions, teaching is an important component that is vital to the development of human minds as well as to global transformation in view of its inherent capacity to promote cognitive development. However, teaching is considered effective only if it results into learning (Coe, Aloisi, Higgins, \& Major, 2014; Kyriakoulis et al., 2016). It is even argued that traditional teaching methods, such as teacher-centered methods, make students passive learners and prevent students from playing an active role in the educational teaching system.

This clearly contrasts with the ethos of developmental theories that encourage educators to design learning environments that challenge and support students in moving to higher levels of intellectual and psychological development. The need to rectify this obvious gap and to ensure higher order learning must have been instrumental in designing and using multiple teaching methods by educators in higher learning institutions (Coe et al., 2014; Cordingley et al., 2015; Ko \& Sammons, 2013; Paolini, 2015).

Methods of teaching and learning have become a top priority problem in nursing. Indeed, it has long been 
acknowledged the significance of efficient learning methodologies in nursing and medical education (Armstrong \& Rispel, 2015; Rutherford-Hemming, 2012). Nurse educators are not born knowing how to teach, as such, becoming effective at teaching requires special knowledge and skills (Clark, 2008).

Teaching methods among teachers and learners are critical elements of teaching and learning (Chan, 2013). For example, Carpenter et al. (2013) noted that teaching methodologies influence the performance of students and the future use of knowledge gained, so nurse educators in higher institutions of learning (HIL) should be aware of the use of evidence-based teaching methods (Day-Black, 2015; Jinks, 2007; Patterson \& Klein, 2012). According to Akiode et al. (2010), a research in Nigeria identified the need for enhancement in how nursing students are taught in schools and clinical positioning. There is no specific teaching method that is widely acceptable, but any teaching method taken should be learning-oriented, student-focused, and satisfy the abilities and expertise criteria for a specific professional skill (Devlin \& O'Shea, 2012). Studies have shown that adopting innovative learning techniques is a challenge for nurse teachers, despite being outstanding to help learners learn efficiently.

Literature suggests that learners prefer the techniques of teaching that promote student learning as they help speed up the learning pace. The learning of learners is produced more efficient through active participation, and this has a major effect on their academic performance and professional skills (Cleary, Happell, Lau, \& Mackey, 2013; Day-Black, 2015). In addition, involving learners in their education enables nursing educators assess their techniques of teaching and enhance their abilities. Effective learning techniques then appear to be the foundation of sound education and efficient nursing practices (Kyriakoulis et al., 2016; O'connor \& Yanni, 2013; Owens, 2017).

While it may be true that nursing educators clarify their knowledge and implementation of the concepts of teaching and learning in nursing education organizations as linked to nursing practice, there are a number of challenges that have been hurdles to the use of teaching techniques that support student-centered learning in South West Nigeria. These include: manpower shortages, health policies, insufficient facilitation abilities, and resource constraints (Agbedia, 2012; Chopra, 2014).

It has been observed that effective teaching methods are lacking in nursing educational HIL. As such, student nurses are not able to develop their knowledge (Chi \& Wylie, 2014; Chopra, 2014; Dufresne, Gerace, Leonard, Mestre, \& Wenk, 1996; Nilesh, Preeti, Mayur, \& Kantharia, 2011). This further strengthens the need for quality teaching methods and effective learning of nursing students in nursing HIL (Aspegren, 1999; Devlin \& O'Shea, 2012; Devlin \& Samarawickrema, 2010; LoBiondo-Wood \& Haber, 2014). Therefore, the challenge to nurse educators, nursing students and nursing service personnel is to work together to design a teaching methods that supports students learning educational system. It has also been observed that the teaching methods used for teaching and learning are directly linked to the development and transformation of the learners' minds in the context of teaching and learning (Arce, Bodner, \& Hutchinson, 2014; McCartney \& Morin, 2005; Won \& Wong, 1987). As such, these challenges affecting nursing training globally and in Nigeria form the focus of this study.

\section{Characteristics of nursing institutes in South West Nigeria}

The nursing institutes in South West Nigeria are characterized by university and hospital based education. In the university based institution, the nursing students are trained on evidence based knowledge education. Its takes a period of five years to complete the program (Agbedia, 2012). In hospital based institution, the nursing students training is more practical oriented and benefit from closed clinical supervision and mentorship from the medical professionals. This program takes a period of three years (Anyigor, Ekuma, Ominyi, \& Agom, 2015). This means if an individual want to acquire a Bachelor of Nursing Science (BNSc) qualification, they attend a university based institution. While someone who want a diploma certificate (RN) goes to hospital based institution

\section{Research Design}

The study commenced with acquisition of ethical approval from the Humanities and Social Sciences Research Ethics Committee of the University of KwaZulu-Natal (Protocol reference number: HSS/0610/016M). The study used a phenomenological approach to explore the experience of nursing educators in teaching methods as well as the challenges faced by nursing education institutions in South West Nigeria. There are six states in South West Nigeria: states of Lagos, Ogun, Oyo, Osun, Ondo and Ekiti. The study was carried out in two states: Ogun State and Osun State. These states and the three institutions that served as the setting of the research were selected using purposeful sampling technique. The tertiary institutions offering Bachelor of Nursing Science and diploma programs were used.

The study population consisted of nurse educators in selected nursing education institutions in South West Nigeria currently working as lecturers. The study was attended by fifteen nurse educators ranging from junior lecturers to 
associate professors from the three nursing institutions. Data collection employed semi-structured in-depth individual interviews with open-ended questions to gain a thorough understanding of the nurse educators' experiences as they relate to the methods of teaching they use.

All interviews were first recorded in audio with the interviewees' permission. Thereafter, the recorded audio tapes were transcribed verbatim. Using thematic content analysis, before being analyzed using NVivo 10. The essence of data analysis is to show the outcome of the raw data and the key findings. In this study, the general inductive approach was used to analyse this qualitative study. Themes and sub-themes were developed from the raw data after coding process as related to the objectives of the study.

\section{Results}

The findings of this study arise directed from the analysis of the raw data, not from priori expectation. Coding process was done after data cleaning, with the objectives of the study in mind provided a focus of the relevant information from the raw data. The identified challenges to effective teaching and learning in nursing education institutions in South West Nigeria were classified under the following themes that emerged:

- Students' inadequate preparedness for higher education

- Teachers' inadequate facilitation skills

- Misconceptions about the practices of nursing educators

- Resource constraints

- Resistance to change

- Lack of inception

Table 1. Summary of the findings

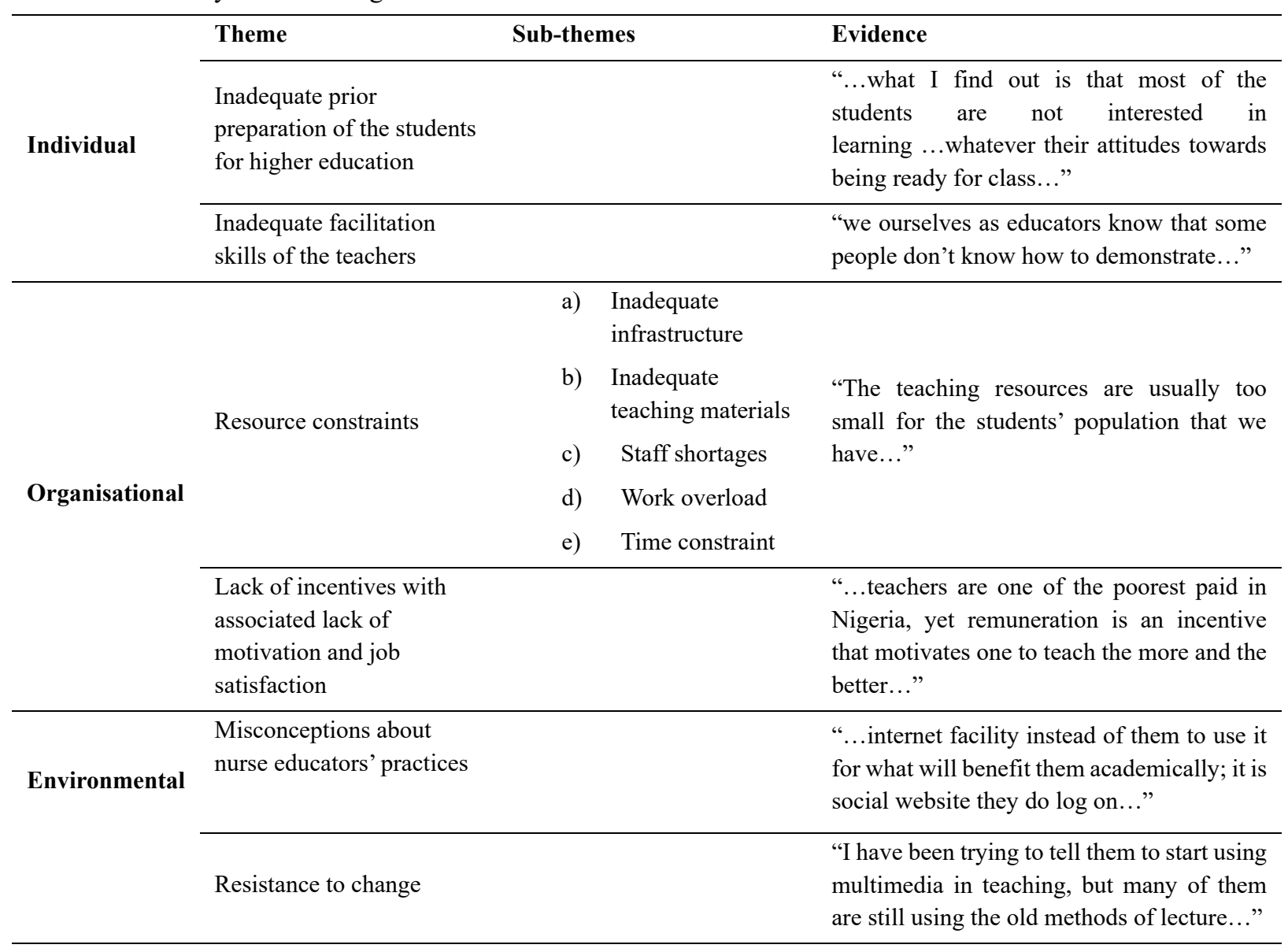




\subsection{Inadequate Preparedness of the Students for Higher Education}

The study identified inadequate prior preparation of the students as a hurdle to teaching and effective learning among nursing students. Participants reported that this lack of preparedness of the students hinders effective facilitation and learning. It was reported that students have problems grasping knowledge after reading and this together with their poor attitudes towards learning constitute challenge in the teaching-learning process. This is well exemplified by the following interview excerpts:

"...what I find out is that most of the students are not interested in learning ... whatever their attitudes towards being ready for class..." (P07)

"....students do not want to read again, that is the challenge I am facing now. Instead of them taking their books and reading, they prefer to chat on their phones and to log on to the internet to get information. They don't like sitting down to read. If you go to our library now, you will find just about 3 or 4 of them reading..." (P04)

\subsection{Deficient Facilitation Skills of the Teachers}

Data revealed inadequate facilitation skills on the part of the teachers as another challenge to quality teaching. Participants pointed out the detriment to nursing education of a lack of competence to facilitate teaching and learning among nurse educators. They reported that the predominant teaching pattern in nursing educational institutions in Nigeria is the teacher-centered methods. The nurse educators see themselves as experts in the subject matter, hence the students become spectators and passive learners. This challenge affects the quality of the training given to nursing students. The excerpt below aptly corroborates this:

“...we ourselves as educators know that some people don't know how to demonstrate, they don't know how to explain, we can only come to class to lecture, so that kind of a thing is also a factor that affect the teaching method..." (P03)

\subsection{Misconceptions About Nurse Educators' Practices}

Misconceptions about teaching and learning stand out equally as a major challenge in the study setting to provide quality nursing education. Participants reported that students prefer taking notes in class and thus use a teacher-oriented approach to teaching. Some educators even argue that the internet is more of a distraction to the current students than a learning aid. Participants also added that group presentations were not a useful method in terms of facilitation. This is reflected in the following extracts:

“...lecturer will do a lot of work by getting information from different sources and give it to the student...because students like to take notes and you want them to have a point of reference so that whatever information they give you in exam can be uniform..." (P02)

"This internet facility instead of them to use it for what will benefit them academically; it is social website they do log on to and that has been the source of distraction to the students." (P01)

"Like group presentation is not effective, is not beneficial but just as I said that I saw that the method is not really beneficial though is needed so we can cover a lot. I discovered that students do not maximize..." (P03)

\subsection{Lack of Incentives With Associated Lack of Motivation and Job Satisfaction}

Lack of motivation consequent on poor incentives and other related factors stand out as another major challenge to the teaching strategies employed in nursing education. Participants reported that they are underpaid considering the work they do. They expressed that this rather poor remuneration tends to weigh down their spirit culminating in low motivation with negative consequences on individuals' efficiency in facilitating teaching and learning. Many recall that the poor salaries paid to teachers, dampens morale and the teachers' zeal at teaching and learning. Other participants state that fallout of the poor incentive is a lack of job satisfaction, which equally affects facilitation of students' learning. The excerpts below buttress this further:

"Another thing is that teachers are one of the poorest paid in Nigeria. We are nowhere as far as remuneration concerned, yet remuneration is an incentive that motivates one to teach the more and the better..." (P03)

"....if the government can just pay commensurable money; something commensurable to the input of the teachers it will serve as an inducement to do better..." (P15)

"....another thing is the remuneration because is ultimate for job satisfaction. You know when you see that you are not well remunerated it can affect your job satisfaction and service delivery..." (P02)

\subsection{Resource Constraint}

In this study, the theme resource constraint consists of six sub-themes based on narratives of the participants. These 
include:

- Inadequate infrastructure

- Inadequate teaching materials

- Shortage of staff

- Work overload

- Time limit.

\subsection{Inadequate Infrastructure}

Participants identified inadequate infrastructure as a hurdle to the provision of conducive working environment that is needed for productive teaching and learning practices. A good number of the participants explained that the infrastructures available are insufficient; in terms of classroom for the student, class size, offices for the staff and modern gadgets that have been proven to enhance students' engagement in class and facilitate learning. The comments below exemplified this:

"The teaching resources are usually too small for the students'population that we have [researcher: you mean the classroom?] For example, my department we are short of classroom and things can be better." (P13)

"I think is getting more facilities available and of course if modernizing the structures. The trend is not using very big large lecture theatres again but here we still use big large lecture theatres because of the large number of students...for a small group discussion you need a different seating arrangement not the traditional seating arrangement." (P15)

"...lack of facilities especially ICT... that can be used to enhance teaching are the major challenges. So they should provide facilities in terms of offices for staff, internet facility...” (P12)

\subsection{Inadequate Teaching Resources}

A good number of the participants equally reported inadequate teaching resources as another factor influencing the choice of teaching methodology and quality of teaching. Interviewee explained further that resources such as electricity, internet connectivity and anatomical models for demonstration are not readily available for use. The quotes below bear eloquent testimony to this:

"There is no light now, no fuel to run the generator, no internet connectivity... All these things are frustrating and sometimes you want to throw everything away. Definitely, the output will be affected... When the resources are there, there is no reason for one not to work." (P14)

"Another challenge is in the area of facilities for teaching. For example, I teach maternal and child health. Recently, I was in the lab to teach students and hmm it was anatomy and physiology of the female reproductive system and I needed anatomical model. I needed manicure and manikin with other things to effectively demonstrate to students before they could go to the hospital but there was none." (P12)

\subsection{Shortage of Staff}

Participants also reported that shortage of staff is a challenge to efficient teaching practices. At present, the number of nursing academic staff vis-à-vis the nursing students' population has become a mismatch. While it could be argued that there are existing policies guiding student-lecturer ratio, it is obvious that they are not being adhered to. The extracts below corroborate this:

"There is shortage of staff compared to number of students that we have. When the educators are less than stipulated number of educators that should be in an institution, the strategies adopted may not be effective...I think that is one of the major challenges because the available educators get burnt out easily due to work overload" (P08)

"There has been an astronomical increase in the number of students without having corresponding increase in the number of teachers." (P15)

"We are short staffed here, we are looking for teachers, so those are the things that are frustrating us." (P06)

\subsection{Work Overload}

Work overload is another factor identified by participants as a constraint to effective teaching and learning. Participants reported that large class sizes have a big influence on the choice of teaching and learning strategies they adopt. Some participants narrated further that due to work overload, students are not well equipped for the task of being a nurse. The excerpts below buttress this: 
"The challenge has been work overload ... let me say generally in Nigeria you have this large number of students in class and with few lecturers so you have a lot of students that you need to teach. Work overload is really high and that has really impacted my efficiency." (P11)

“...we have seventeen academic staff for both full-time and part-time students and in the full-time programme alone we have over five hundred students. So they should hire more academic staff so that the number of courses taken by individual lecturers per semester can be cut down, so that we can have more time to prepare for the student...”(P12)

"You have so many classes to take okay. As a young lecturer, you have your own classes to take, you have the university courses to take. Where you are not supposed to be taking more than a class, you are taking like three classes. Do you get that? It's really a big challenge?" (P14)

\subsection{Time Constraint}

Time constraint emerged as yet another constraint to quality teaching practices among nurse educators in the study setting. Participants expressed that the lecture method has been widely adopted by nurse educators because of the limited time allocated to teach a particular course. To this end, suitable time allocation for a course will empower the teachers to facilitate learning effectively. The quotes below reflect this:

"...when you are lecturing you don't engage the student; you don't get them to participate because you are desirous of completing what you want to give them within that limited time you have..." (P15)

"In only part one regular programme we have about 100 students. So that is a huge challenge where you have to teach 100 students a concept in nursing ...requires discussion and demonstration but you don't have that time. You have been allotted 2 or 3hours twice in a week." (P12)

"We are all on our PhD so the time is a constraint. We don't have that time to be able to give the best to the students. So we are running our PhD full-time and at the same time teaching. I think these are the major important challenges we face for now." (P12)

"Most of the times I will talk about teaching-learning methods because when you are still talking about Teaching Methodologies most people are still more inclined to the concept of teaching (give). So I think the human support is another big thing. We are still trying to do that but it is not yet established as it should be." (P13).

\subsection{Lack of Funds}

Data revealed that poor funding of higher nursing education is a huge challenge to excellence in teaching and learning nursing. Participants argued that inadequate funding has hampered nurse educators' engagement in quality research and knowledge generation. The extracts below speak volume to this:

"You want to do research you don't have money for research, you want to update yourself, limited resources, you have to use your salary which is not even enough for you." (P14)

"I have to buy my own textbooks without allowances for it. I have to pay for the internet I use to get information so hmmm sometimes you have to buy the chair you sit on by yourself. so it is really a big challenge.” (P14)

"Well I don't want to go into the economy of the nation, but our remuneration, the salary we are paid is still not encouraging considering the hardship we are passing through in the system. Well, even though the pay is not encouraging, we don't have a choice than to manage." (P109)

\subsection{Resistance to Change}

The following excerpts aptly support this:

"I have been trying to tell them to start using multimedia in teaching, but many of them are still using the old methods of lecture, demonstration and .... People don't believe in moving forward very fast.” (P06)

"Most of the time we normally limit ourselves to lecturing; we call it lecturing that is just teaching and at times we use discussion. These are the two prominent ones we use in the classroom." (P12)

\section{Discussion}

This study explores the experiences of nurse educators and challenges encountered in South West Nigeria in teaching and learning of nursing education institutions. This study highlighted a number of factors that posed challenges to nursing student teaching and learning in South West Nigeria. An individual is influence to action when they are motivated (Marquis \& Huston, 2009; Martin, 2005; McLean \& Mallett, 2012). From these findings, nurse educators reported inadequate preparedness of the nursing students to higher education. This hindered the effective facilitation and learning of the students since the students had difficulties in grasping content after 
studying besides their negative attitude towards nursing education. Contrary to the findings in (Byrne et al., 2012; Subhan, 2014) that showed learners lack interest in education and are not interested in teaching and learning, we can conclude from our findings that learners are ill-prepared for higher education. According to participants, it is this ill preparedness that negatively impacts learners' ability to decode subject matter and at the same time influenced by the choice of teaching methods.

This study found that $67 \%$ of the participants had misconceptions that inadvertently affected the choice of teaching methods used by nurse educators and the quality of teaching by extension. Prominent among these misconceptions is the belief among nurse educators that nursing students prefer class note-taking rather than learning aid, and the idea that group presentations are not effective facilitation methods. This had undoubtedly helped to consolidate traditional methods in South West Nigeria's nursing educational institutions.

From this study it is crystal clear that traditional methods are the predominant teaching methods in nursing schools in Southwest Nigeria. On the contrary, each student is a unique individual, and the diversity of teaching and learning capacity among nursing students makes it hard to believe that traditional teaching methods will benefit each learner. Furthermore, the over-reliance on traditional methods may not be unrelated to the grandiose perception of nursing educators as the custodian of knowledge and subject matter experts.

The net result of a lack of diversity in the method of teaching is that students tend to become bored, frustrated, lose interest in subject matter and thus become inadequately prepared. This finding is consistent with the submission by Mwale and Kalawa (2016, p. 6) that educators' inadequate facilitation skills are a huge challenge in nursing education. Moreover, these authors (Grassley \& Lambe, 2015, p. 361; Khademolhosseini, Vanaki, Memarian, \& Ebadi, 2012, p. 485) established that the future of nursing lies is in the quality of nursing education by nursing educators (WHO, 2009). Others are the widespread notion that the student's use of technology is becoming increasingly distracted. It should be observed that the present generation of learning nursing students are not only living in an age of technological explosion, they are also digital natives. Therefore, it would appear that the technological way is an effective method of facilitation and one that easily excites and sustains their interest in learning. This corroborates Krau (2015) claims that learners will be motivated by the use of technology in teaching and learning to engage in teaching learning process. Therefore, technology-oriented strategy plays a major role for nursing students in Southwest Nigeria's nursing educational institutions (Krau, 2015).

The revelation that $87 \%$ of the nursing educators interviewed received poor wages coupled with a lack of incentives resulted in poor motivation and related lethargy. This finding is similar to those found by (Eta, Atanga, Atashili, \& D'Cruz, 2011; Gaber \& Moustafa, 2015; A. Hussein \& R. G. Hussein, 2013; Khammarnia, Haj Mohammadi, Amani, Rezaeian, \& Setoodehzadeh, 2015; Mthiyane \& Habedi, 2018; Sabari, 2012; Yelkpieri, Namale, Esia-Donkoh, \& Ofosu-Dwamena, 2012), These authors identified the lack of motivation among educators to cause loss of job satisfaction and therefore low productivity. It should be noted that in order to be employable, nursing educators invest so much in their own education. As such, they may be quite demoralized at the low wages they are paid. Having this in mind, an increase in the salary of nursing educators and the provision of incentives will most likely provide the impetus needed to improve teaching and learning in nursing institutions.

Another challenge unmasked by this study is that lack of funding in institutions of nursing education adversely affects the quality of nursing education. A comparable research carried out in another environment (Yelkpieri et al., 2012) is identical to the results of this research that absence of funding is a challenge in tertiary institutions in Ghana and other developing countries such as Nigeria. Despite the fact that finances will not solve all the challenges in nursing education institutions, however, efficient facilitation is essential in many ways. It is therefore thought that the release of funds for research, conference and workshop sponsorship will go a long way in helping to accumulate expertise that could improve quality teaching and learning.

Yet significant is the issue of resource constraints emerged in this study as a theme. Five sub-themes emerged: (i) inadequate infrastructure, (ii) inadequate teaching resources, (iii) staff shortage, (iv) work overload, (v) time constraints. The link between nurse educators' role and the issue around theory-practice gap in nursing profession demands an intervention. Inadequate infrastructure and teaching and learning resources were identified as a challenge to effective working condition of nurse educators. This inadequacy was in terms of few available lecture rooms for the nursing students, lecture room size versus student ratio, inadequate staff offices for the nurse educators and lack of amenities like air conditioner, projector and stable electricity in lecture rooms for effective facilitation of nursing students. These needs have been declared non-negotiable in support of effective teaching and learning by scholars who declare the availability of adequately modernized infrastructure in institutions of nursing education as a necessity for improving quality education (Adelabu, 2008; Ahmad, Ching, Yahaya, \& Abdullah, 2015; Bell, Rominski, Bam, Donkor, \& Lori, 2013; Daniels, Fakude, Linda, \& Modeste, 2015, pp. 8-16; 
Lagoune, 2012; Rich \& Nugent, 2010). This is because learning comes from internal and external environments, and nurse educators will need to select methods of teaching that support student learning for effective nursing students teaching and learning. Environmental factors such as inadequate educational facilities and amenities in nursing institutions in South West Nigeria are factors that threaten quality teaching practice.

Therefore, in order to close the gap between theory and practice in nursing practice for nursing students, the following challenges should be addressed first: shortage of nursing educators, overload of work and allocated time for nursing student teaching. In addition, work overload is another factor reported as a constraint to effective methods of teaching and learning in South West Nigeria due to a shortage of nurse educators. In fact, $93 \%$ of the participants reported that the resources of manpower are inadequate compared to the increasing number of nursing students rolling each year. These results are identical to those reported in (Agbedia, 2012; Albarran \& Rosser, 2014; Bell et al., 2013; Budgen \& Gamroth, 2008; Croxon \& Maginnis, 2009; GormIey, 2003; Herrman, 2008 ; Luhanga, Billay, Grundy, Myrick, \& Yonge, 2010; Mason, Shuman, \& Cook, 2013; Norman, Buerhaus, Donelan, McCloskey, \& Dittus, 2005; O'Flaherty \& Phillips, 2015; Saarikoski, Isoaho, Warne, \& Leino-Kilpi, 2008; Sarmiento, Laschinger, \& Iwasiw, 2004; Sedgwick \& Harris, 2012).

Additionally, it was observed that shortage of professional nurses is attributed to low recruitment during structural adjustment program. The effect is seen in nursing workforce that is skewed towards older workers than the general workforce. As a result, a large number of nurses are retiring from the profession.

Inadequate time allocation to lectures coupled with large classes were also reported to be a major concern for nurse educators. This is because time allocation for lectures is vital to facilitate nursing student learning effectively. As such nurse educators experienced dissension from their institutions since they were put under the pressure of managing large class size without adequate allocated time to facilitate teaching and learning. Similar findings were also reported by (2016, p. 124) who identified large class size as a big challenge for the student and nurse educators in nursing education. The teaching and learning strategy to facilitate learners is influenced by class size. The National Universities Commission (NUC) policy on lecturer-student ratio of ratio 1:10 in the Federal Republic of Nigeria is to promote and enhance excellent training of students. Similar findings were reported by (Adelabu, 2008; Rafiee, Moattari, Nikbakht, Kojuri, \& Mousavinasab, 2014, p. 41) that showed that $60 \%$ of the nursing educators still use traditional method of teaching to facilitate nursing students. This shows the nursing educators' reluctance to revolutionize their methods of teaching and learning as such contributes to this study's teacher's resistance to change.

Traditional methods of teaching are viewed as teacher-oriented method of communication with the learners. The teacher is the sole source of the knowledge while the learners are passive receivers with minimal involvement thus leading to low assimilation of the students. While contemporary teaching and learning method is student-focused, it is based on assisting the student to learn. This is achieved through effective interaction with the student and good communication flow between the nurse educators and the student nurses. Although there is need for the use of innovative teaching and learning methods in nursing education institutions, this study identified resistance to change from the use of traditional methods. Hence, there is need for a transformation of teaching and learning methods in nursing educational institutions in South West Nigeria, a finding that is consistent with the findings in (Adib-Hajbaghery \& Aghajani, 2011; Brannagan et al., 2013; Hadzimehmedagic \& Akbarov, 2013; Ishkov \& Leontiev, 2015; Robb \& Gerwick, 2013).

\section{Conclusion}

In conclusion, nursing education is the foundation to the future of nursing profession and nursing practice. Therefore, the following working conditions will enable nurse educators to use teaching and learning methods that support nursing students learning that are student-centered: Regulation of the number of nursing student in-take for admission in order to produce proficient nurses, improving the financial base of nursing educational institutions as well as the financial status of nurse educators would most likely bring about desired improvement in the quality of teaching and learning in nursing education in Southwest Nigeria, provision of incentives and commensurable salary, and adequate teaching resources to nurse educators. These would greatly motivate nursing educators and enhance their effective facilitation of nursing training and skills. Additionally, there should be collaboration among nursing educators, students, nursing service professionals and other stakeholder. This will greatly enhance nursing education and help bridge the gap in nursing training between the academic and clinical working environment.

\subsection{Limitations to the Study}

Due to the small sample population, the findings from this study cannot be generalized. As such, further research is required to include nursing students and their perception of teaching and learning techniques of the nurse 
educators.

\section{Acknowledgements}

We thank all the nurse educators who took their time to participate in this study. Research reported in this publication was supported by the Fogarty International Center (FIC), NIH Common Fund, Office of Strategic Coordination, Office of the Director (OD/OSC/CF/NIH), Office of AIDS Research, Office of the Director (OAR/NIH), National Institute of Mental Health (NIMH/NIH) of the National Institutes of Health under Award Number D43TW010131. The content is solely the responsibility of the authors and does not necessarily represent the official views of the National Institutes of Health. In addition, financial support for this research was also provided from School of Health Sciences, University of KwaZulu-Natal.

\section{Competing Interests Statement}

The authors declare that there are no competing or potential conflicts of interest.

\section{References}

Adelabu, M. (2008). Making education services work for rural population: A case study of Egbedore local government of Osun State, Nigeria. The Journal of International Social Research, 1(4), 36-59.

Adib-Hajbaghery, M., \& Aghajani, M. (2011). Making education services work for rural population: A case study of Egbedore local government of Osun State, Nigeria. Retrieved from https://www.webmedcentral.com/article_view/1746

Agbedia, C. (2012). Re-envisioning nursing education and practice in Nigeria for the 21 st century. Open Journal of Nursing, 2, 226-230. https://doi.org/10.4236/ojn.2012.23035

Ahmad, C. N. C., Ching, W. C., Yahaya, A., \& Abdullah, M. F. N. L. (2015). Relationship between constructivist learning environments and educational facility in science classrooms. Procedia - Social and Behavioral Sciences, 191, 1952-1957. https://doi.org/10.1016/j.sbspro.2015.04.672

Akiode, A., Fetters, T., Daroda, R., Okeke, B., \& Oji, E. (2010). An evaluation of a national intervention to improve the postabortion care content of midwifery education in Nigeria. International Journal of Gynecology \& Obstetrics, 110(2), 186-190. https://doi.org/10.1016/j.ijgo.2010.05.003

Albarran, J. W., \& Rosser, E. A. (2014). The challenges facing midwifery educators in sustaining a future education workforce. Midwifery, 30(8), 949-955. https://doi.org/10.1016/j.midw.2013.07.016

Anyigor, C. N., Ekuma, C. E., Ominyi, J. N., \& Agom, D. A. (2015). A Reform in the Department of Nursing Sciences, Ebonyi State University, Abakaliki, Nigeria Using Transformational Leadership Style. International Journal of Science and Research (IJSR), 4(4), 107-112.

Arce, J., Bodner, G., M., \& Hutchinson, K. (2014). A study of the impact of inquiry-based professional development experiences on the beliefs of intermediate science teachers about "Best Practices" for classroom teaching. Science and Technology, 2(2), 85-95. https://doi.org/10.18404/ijemst.83181

Armstrong, S. J., \& Rispel, L. C. (2015). Social accountability and nursing education in South Africa. Global Health Action, 8, 5-111. https://doi.org/10.3402/gha.v8.27879

Aspegren, K. (1999). BEME Guide No. 2: Teaching and learning communication skills in medicine-a review with quality grading of articles. Medical teacher, 21(6), 563-570. https://doi.org/10.1080/01421599978979

Bakon, S., Craft, J., Christensen, M., \& Wirihana, L. (2016). Can active learning principles be applied to the bioscience assessments of nursing students? A review of the literature. Nurse Education Today, 37, 123-127. https://doi.org/10.1016/j.nedt.2015.11.030

Bell, S. A., Rominski, S., Bam, V., Donkor, E., \& Lori, J. (2013). Analysis of nursing education in Ghana: Priorities for scaling-up the nursing workforce. Nursing \& Health Sciences, 15(2), 244-249. https://doi.org/10.1111/nhs.12026

Brannagan, K. B., Dellinger, A., Thomas, J., Mitchell, D., Lewis-Trabeaux, S., \& Dupre, S. (2013). Impact of peer teaching on nursing students: Perceptions of learning environment, self-efficacy, and knowledge. Nurse Education Today, 33(11), 1440-1447. https://doi.org/10.1016/j.nedt.2012.11.018

Budgen, C., \& Gamroth, L. (2008). An overview of practice education models. Nurse Education Today, 28(3), 273-283. https://doi.org/10.1016/j.nedt.2007.05.005

Byrne, M., Flood, B., Hassall, T., Joyce, J., Arquero Montaño, J. L., González González, J. M., \& 
Tourna-Germanou, E. (2012). Motivations, expectations and preparedness for higher education: A study of accounting students in Ireland, the UK, Spain and Greece. Accounting Forum, 36(2), 134-144. https://doi.org/10.1016/j.accfor.2011.12.001

Carpenter, S., Delugach, H., Etzkorn, L., \& Utley, D. (2013). How instructional format (voice and modality) influences subsequent performance: An empirical study. International Journal of Teaching and Learning in Higher Education, 25(1), 59-65.

Chan, Z. C. (2013). A systematic review of critical thinking in nursing education. Nurse Education Today, 33(3), 236-240. https://doi.org/10.1016/j.nedt.2013.01.007

Chi, M. T., \& Wylie, R. (2014). The ICAP framework: Linking cognitive engagement to active learning outcomes. Educational Psychologist, 49(4), 219-243. https://doi.org/10.1080/00461520.2014.965823

Chopra, J. (2014). Students'reflections on teaching methodology in anatomy. Asian Journal of Medical Sciences, 5(1), 47-51. https://doi.org/10.3126/ajms.v5il.8039

Clark, C. C. (2008). Classroom Skills for Nurse Educators. Ontario, Canada: Jones \& Bartlett Learning.

Cleary, M., Happell, B., Lau, S. T., \& Mackey, S. (2013). Student feedback on teaching: Some issues for consideration for nurse educators. International Journal of Nursing Practice, 18, 62-66. https://doi.org/10.1111/ijn.12018

Coe, R., Aloisi, C., Higgins, S., \& Major, L. E. (2014). What makes great teaching? Review of the underpinning research (pp. 1-57). UK: Centre for Evaluation and Monitoring.

Cordingley, P., Higgins, S., Greany, T., Buckler, N., Coles-Jordan, D., Crisp, B., . . Coe, R. (2015). Developing great teaching: Lessons from the international reviews into effective professional development. Retrieved from London.

Croxon, L., \& Maginnis, C. (2009). Evaluation of clinical teaching models for nursing practice. Nurse Education in Practice, 9(4), 236-243. https://doi.org/10.1016/j.nepr.2008.06.004

Daniels, F. M., Fakude, L. P., Linda, N. S., \& Modeste, R. R. M. (2015). Nurse educators' experiences of case-based education in a South African nursing programme. Curationis, 38(2), 1-8. https://doi.org/10.4102/curationis.v38i2.1523

Day-Black, C. (2015). Gamification: An innovative teaching-learning strategy for the digital nursing students in a community health nursing course. ABNF Journal, 26(4), 90-96.

Devlin, M., \& O'Shea, H. (2012). Effective University teaching: Views of Australian University students from low socio-economic status backgrounds. Teaching in Higher Education, 17(4), 385-397. https://doi.org/10.1080/13562517.2011.641006

Devlin, M., \& Samarawickrema, G. (2010). The criteria of effective teaching in a changing higher education

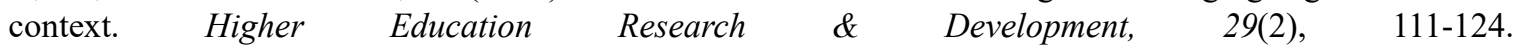
https://doi.org/10.1080/07294360903244398

Dufresne, R. J., Gerace, W. J., Leonard, W. J., Mestre, J. P., \& Wenk, L. (1996). Class talk: A classroom communication system for active learning. Journal of Computing In Higher Education, 7(2), 3-47. https://doi.org/10.1007/BF02948592

Eta, V. E., Atanga, M. B., Atashili, J., \& D’Cruz, G. (2011). Nurses and challenges faced as clinical educators: A survey of a group of nurses in Cameroon. Pan African Medical Journal, 8(28), 1-8. https://doi.org/10.4314/pamj.v8i1.71085

Gaber, M. A., \& Moustafa, M. S. (2015). Development of motivational strategies for nursing students at Zagazig University in Egypt. Journal of Nursing Education and Practice, 5(6), 62-72. https://doi.org/10.5430/jnep.v5n6p62

GormIey, D. K. (2003). Factors affecting job satisfaction in nurse faculty: A meta-analysis. Journal of Nursing Education, 42(4), 174-178. doi:https://doi.org/10.3928/0148-4834-20030401-08

Grassley, J. S., \& Lambe, A. (2015). Easing the transition from clinician to nurse educator: An integrative literature review. Journal of Nursing Education, 54(7), 361-366. https://doi.org/10.3928/01484834-20150617-01

Hadzimehmedagic, M., \& Akbarov, A. (2013). Traditional vs modern teaching methods. Advantages and disadvantages. Paper presented at the 3rd International Conference on Foreign Language Teaching and Applied Linguistics. 
Herrman, J. (2008). Creative Teaching Strategies for the Nurse Educator. Philadelphia: Davis company.

Hussein, A., \& Hussein, R. G. (2013). The attitudes and barriers towards evidence-based practice among nursing educators. Journal of American Science, 9(12), 609-618.

Ishkov, A., \& Leontiev, M. (2015). Interactive teaching methods in small groups of bachelors and construction specialists. Procedia Engineering, 117, 142-147. https://doi.org/10.1016/j.proeng.2015.08.135

Jinks, A. M. (2007). Methodological considerations of undertaking research with clinical mentors in the UK: A critical review of the literature. Nurse Education Today, 27(7), 667-676. https://doi.org/10.1016/j.nedt.2006.09.014

Khademolhosseini, S. M., Vanaki, Z., Memarian, R., \& Ebadi, A. (2012). Semantic divergence in clinical education: Student-centered or student democracy. Iranian Journal of Nursing And Midwifery Research, 17(7), 485-492.

Khammarnia, M., Haj Mohammadi, M., Amani, Z., Rezaeian, S., \& Setoodehzadeh, F. (2015). Barriers to implementation of evidence based practice in Zahedan teaching hospitals, Iran, 2014. Nursing research and practice, 2015, 1-6. https://doi.org/10.1155/2015/357140

Ko, J., \& Sammons, P. (2013). Effective Teaching: A Review of Research and Evidence. England: CFBT Education Trust.

Krau, S. D. (2015). The influence of technology in nursing education. Nursing Clinics of North America, 50(2), 379-387. https://doi.org/10.1016/j.cnur.2015.02.002

Kyriakoulis, K., Patelarou, A., Laliotis, A., Wan, A. C., Matalliotakis, M., Tsiou, C., \& Patelarou, E. (2016). Educational strategies for teaching evidence-based practice to undergraduate health students: Systematic review. Journal of educational evaluation for health professions, 13(34), 1-10. https://doi.org/10.3352/jeehp.2016.13.34

Lagoune, M. N. (2012). The Use of Teaching Materials as a Motivator to Enhance Students' Listening Comprehension in Lectures (Thesis, University of Biskra).

LoBiondo-Wood, G., \& Haber, J. (2014). Nursing Research-E-Book: Methods and Critical Appraisal for Evidence-Based Practice. China: Elsevier Health Sciences. https://doi.org/10.1016/S2155-8256(15)30102-2

Luhanga, F. L., Billay, D., Grundy, Q., Myrick, F., \& Yonge, O. (2010). The one-to-one relationship: is it really key to an effective preceptorship experience? A review of the literature. International journal of nursing education scholarship, 7(1), 1-17. https://doi.org/10.2202/1548-923X.2012

Marquis, B. L., \& Huston, C. J. (2009). Leadership Roles and Management Functions in Nursing: Theory and Application. New York, London: Lippincott Williams \& Wilkins.

Martin, C. A. (2005). Leadership: Make it HOT: The heat is on! Find a new approach to staff management and empowerment. Nursing management, 36(9), 38-45. https://doi.org/10.1097/00006247-200509000-00010

Mason, G. S., Shuman, T. R., \& Cook, K. E. (2013). Comparing the effectiveness of an inverted classroom to a traditional classroom in an upper-division engineering course. IEEE Transactions on Education, 56(4), 430-435. https://doi.org/10.1109/TE.2013.2249066

McCartney, P. R., \& Morin, K. H. (2005). Where is the evidence for teaching methods used in nursing education? MCN: The American Journal of Maternal/Child Nursing, 30(6), 406-412. https://doi.org/10.1097/00005721-200511000-00010

McLean, K. N., \& Mallett, C. J. (2012). What motivates the motivators? An examination of sports coaches. Physical Education \& Sport Pedagogy, 17(1), 21-35. https://doi.org/10.1080/17408989.2010.535201

Mthiyane, G. N., \& Habedi, D. S. (2018). The experiences of nurse educators in implementing evidence-based practice in teaching and learning. Health SA Gesondheid, 23, 1-9. https://doi.org/10.4102/hsag.v23i0.1177

Mwale, O. G., \& Kalawa, R. (2016). Factors affecting acquisition of psychomotor clinical skills by student nurses and midwives in CHAM nursing colleges in malawi: A qualitative exploratory study. BMC Nursing, 15(1), 1. https://doi.org/10.1186/s12912-016-0153-7

Nilesh, C., Preeti, Y., Mayur, C., \& Kantharia, N. (2011). Second year students feedback on teaching methodology and evaluation methods in pharmacology. National Journal of Physiology, Pharmacy and Pharmacology, 1, 23-31. https://doi.org/10.5455/njppp.2011.1.23-31 
Norman, L., Buerhaus, P. I., Donelan, K., McCloskey, B., \& Dittus, R. (2005). Nursing students assess nursing education. Journal of Professional Nursing, 21(3), 150-158. https://doi.org/10.1016/j.profnurs.2005.04.003

O'connor, L. G., \& Yanni, C. K. (2013). Promotion and tenure in nursing education: Lessons learned. Journal of Nursing Education and Practice, 3(5), 78-88. https://doi.org/10.5430/jnep.v3n5p78

O'Flaherty, J., \& Phillips, C. (2015). The use of flipped classrooms in higher education: A scoping review. The internet and higher education, 25, 85-95. https://doi.org/10.1016/j.iheduc.2015.02.002

Owens, J. (2017). Life balance in nurse educators: A mixed-methods study. Nursing Education Perspectives, 38(4), 182-188. https://doi.org/10.1097/01.NEP.0000000000000177

Paolini, A. (2015). Enhancing teaching effectiveness and student learning outcomes. The Journal of Effective Teaching, 15(1), 20-33.

Patterson, B. J., \& Klein, J. M. (2012). Evidence for teaching: What are faculty using? Nursing Education Perspectives, 33(4), 240-245. https://doi.org/10.5480/1536-5026-33.4.240

Rafiee, G., Moattari, M., Nikbakht, A. N., Kojuri, J., \& Mousavinasab, M. (2014). Problems and challenges of nursing students' clinical evaluation: A qualitative study. Iranian Journal of Nursing And Midwifery Research, 19(1), 41.

Rich, K. L., \& Nugent, K. E. (2010). A United States perspective on the challenges in nursing education. Nurse Education Today, 30(3), 228-232. https://doi.org/10.1016/j.nedt.2009.10.015

Robb, M., \& Gerwick, M. (2013). Team teaching: A resource guide for nurse educators. Teaching and Learning in Nursing, 8(3), 78-82. https://doi.org/10.1016/j.teln.2013.04.005

Rutherford-Hemming, T. (2012). Simulation methodology in nursing education and adult learning theory. Adult Learning, 23(3), 129-137. https://doi.org/10.1177/1045159512452848

Saarikoski, M., Isoaho, H., Warne, T., \& Leino-Kilpi, H. (2008). The nurse teacher in clinical practice: developing the new sub-dimension to the clinical learning environment and supervision (CLES) scale. International journal of nursing studies, 45(8), 1233-1237. https://doi.org/10.1016/j.ijnurstu.2007.07.009

Sabari, M. H. (2012). The perceive impact of motivation on lecturers' performance in Ahmadu Bello University, Zaria. International Journal of Physical and Social Sciences, 2(8), 317-340.

Sarmiento, T. P., Laschinger, H. K. S., \& Iwasiw, C. (2004). Nurse educators' workplace empowerment, burnout, and job satisfaction: Testing Kanter's theory. Journal of Advanced Nursing, 46(2), 134-143. https://doi.org/10.1111/j.1365-2648.2003.02973.x

Sedgwick, M., \& Harris, S. (2012). A critique of the undergraduate nursing preceptorship model. Nursing research and practice, 2012, 1-6. https://doi.org/10.1155/2012/248356

Subhan, M. S. (2014). Current Pedagogical Teaching Strategies being used by Educators at the Kwazulu Natal College of Nursing Campuses across Varied Subjects and their Views Regarding Innovative Methodologies. Durban University of Technology. Retrieved from http://hdl.handle.net/10321/1262

WHO. (2009). Global standards for the initial education of professional nurses and midwives. Retrieved from

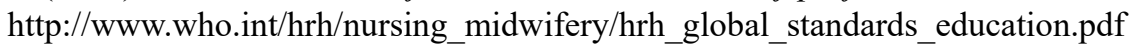

Won, J., \& Wong, S. (1987). Towards effective clinical teaching in nursing. Journal of Advanced Nursing, 12(4), 505-513. https://doi.org/10.1111/j.1365-2648.1987.tb01360.x

Yelkpieri, D., Namale, M., Esia-Donkoh, K., \& Ofosu-Dwamena, E. (2012). Effects of large class size on effective teaching and learning at the Winneba campus of the UEW (University of education, Winneba, 3, 319-332). Ghana: David Publishing.

\section{Copyrights}

Copyright for this article is retained by the author(s), with first publication rights granted to the journal.

This is an open-access article distributed under the terms and conditions of the Creative Commons Attribution license (http://creativecommons.org/licenses/by/4.0/). 